\title{
is
}

\section{Seladin-1: A Possible Neuroprotective Agent in Alzheimer's Disease}

\author{
Sepideh Ghasemi ${ }^{1}$, Sara Abdolahi ${ }^{1,2}$, Hoda Pasand Mojdeh ${ }^{3}$, Maryam Borhani-Haghighi ${ }^{1,4^{*}}$ \\ ${ }^{1}$ Shefa Neuroscience Research Center, Khatam Alanbia Hospital, Tehran, Iran \\ ${ }^{2}$ Department of Pathobiology, School of Veterinary Medicine, Shiraz University, Shiraz, Iran \\ ${ }^{3}$ School of Biology, College of Science, University of Tehran, Tehran, Iran \\ ${ }^{4}$ Department of Anatomy, School of Medicine, Tehran University of Medical Sciences, Tehran, Iran
}

\begin{abstract}
Article Info:
Received: 10 Oct 2016

Revised: 29 Oct 2016

Accepted: 21 Dec 2016
\end{abstract}

\section{ABSTRACT}

Introduction: Alzheimer's disease is a progressive brain dysfunction, which damages and destroys neurons and results in memory loss. Selective Alzheimer's disease indicator-1 (seladin-1) is a gene and protein that is found to be down-regulated in specific areas of the brain affected by Alzheimer's disease. Seladin-1 has neuroprotective properties and inhibits caspase-3 activity, a key mediator of apoptosis. Seladin-1 is a multi-functional protein and independently of its activity as a caspase-3 inhibitor, it acts as a cholesterol biosynthetic enzyme. Cholesterol enhances the formation of lipid rafts inhibits the production of $\beta$-amyloid in the membrane of neural cell. Cholesterol homeostasis disorder in neural cells may enhance susceptibility of cells to the toxic agents. Conclusion: Studies have shown that the level of seladin-1 increases during brain development to prevent the loss of neuronal precursor cells. Estrogen and thyroid hormones stimulate the expression of seladin-1. It seems that seladin-1 may act as a mediator of these hormones.

*Corresponding Author: Maryam Borhani-Haghighi

E-mail: borhanihm@gmail.com 


\title{
سلادين - ا: يك عامل احتمالى حفاظت نورونى در بيمارى آلزايمر
}

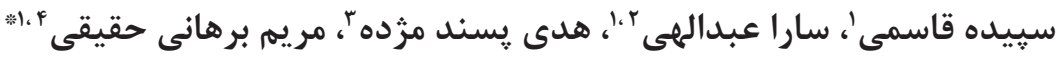 \\ 'مركز تحقيقات علوم اعصاب شفا، بيمارستان خاتمالانبياء، تهران، ايران

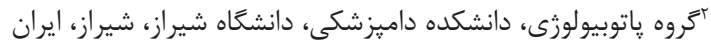

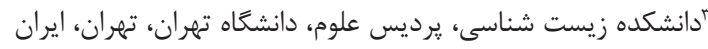

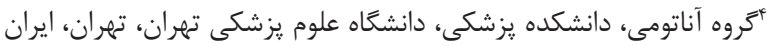

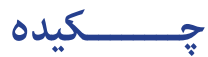

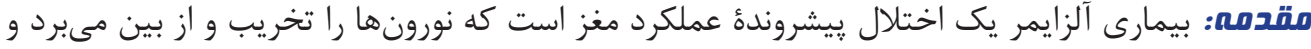

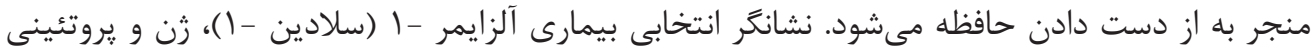

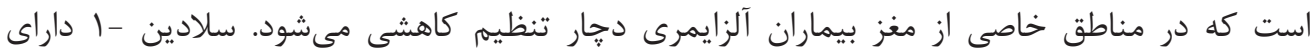

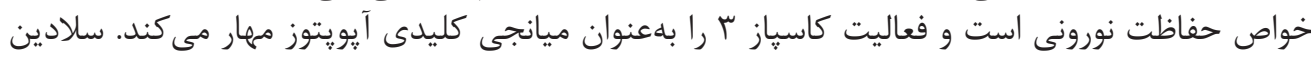

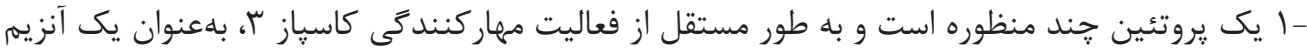

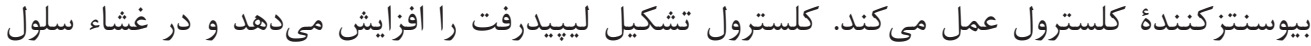

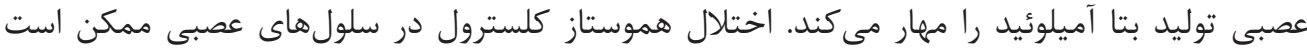

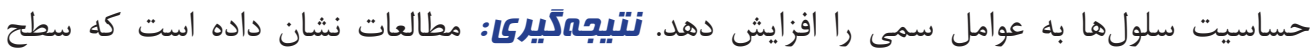

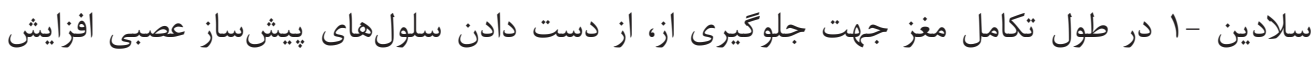

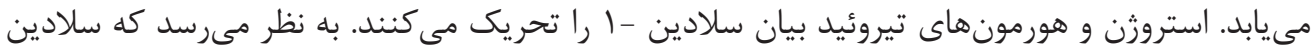

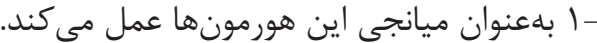

ا. بيمارى آلزايمر

كليد وازهها:

r. عوامل حفاظت نوريدي ب.

$$
\text { " نويسنده مسئول: مريم برهانى حقيقى " }
$$
آدرس الكترونيكى: borhanihm@gmail.com 


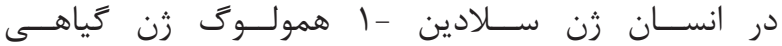
إرابيدو DIMINUTO/DWARF1

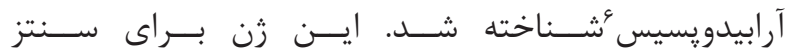

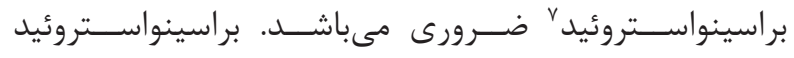

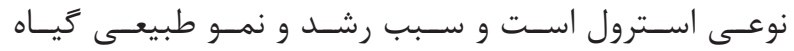

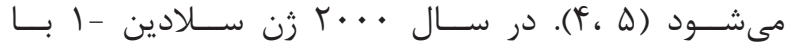

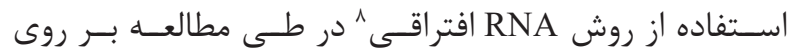

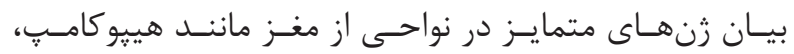

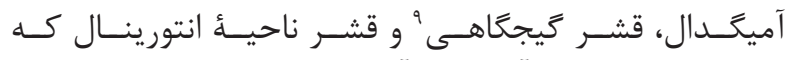

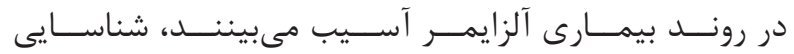

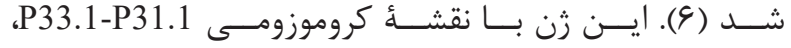

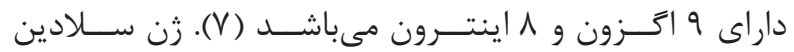

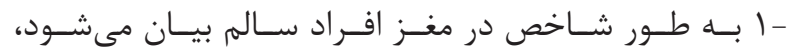

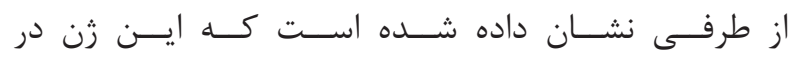

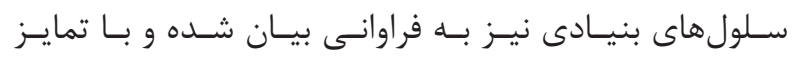

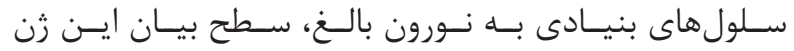

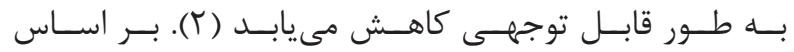

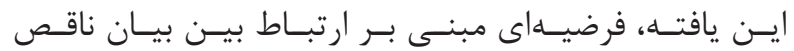

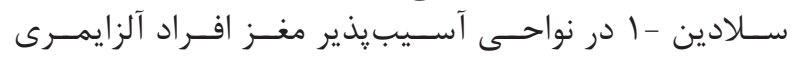

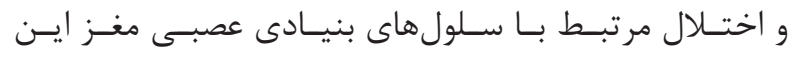

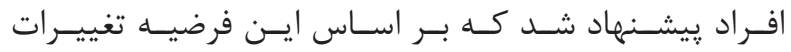

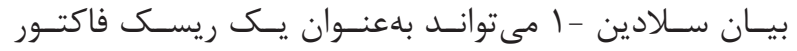

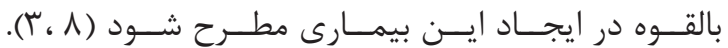
نقش سلادين - ا بهعنوان يك آنزيم

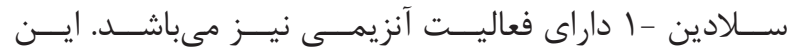

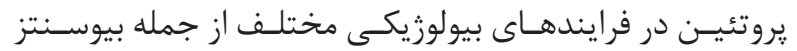

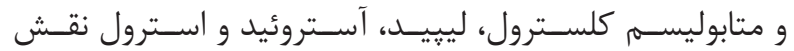

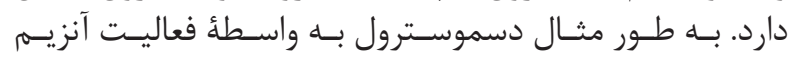

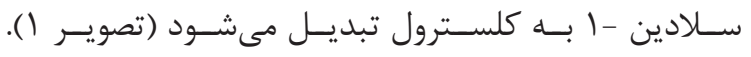

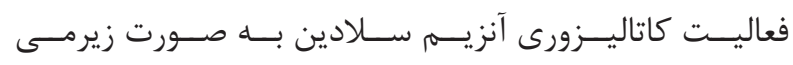

5-alpha-cholest-7-en-3-beta-ol $+\mathrm{NADP}^{+}=5$-alphacholesta-7,24-dien-3-beta-ol+NADPH

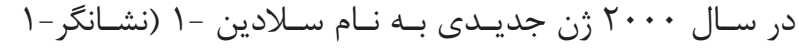

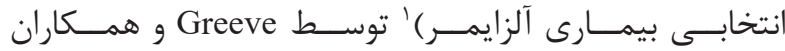

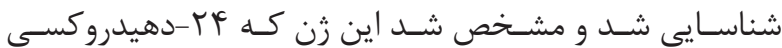

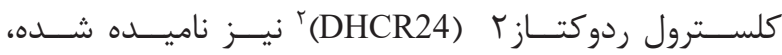

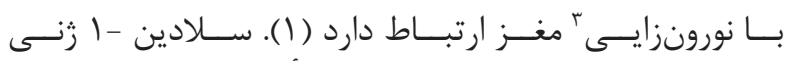

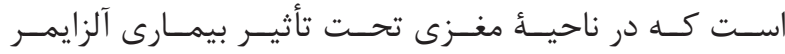

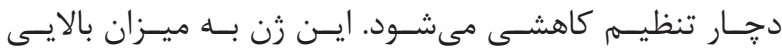

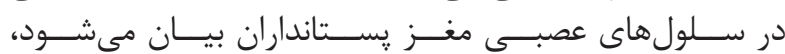

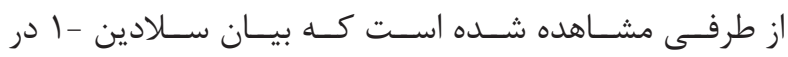

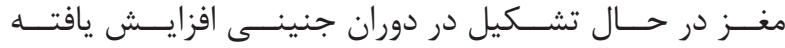

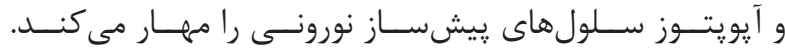

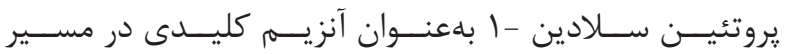

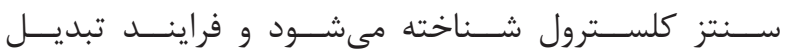

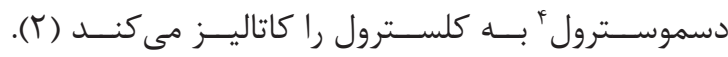

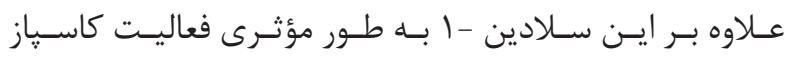

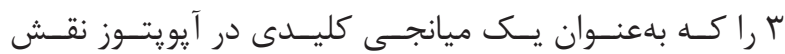

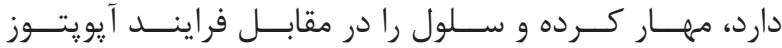

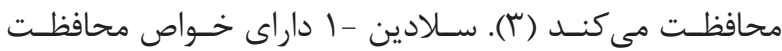

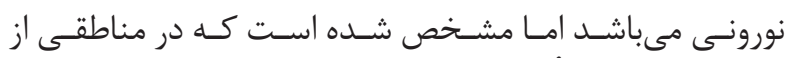

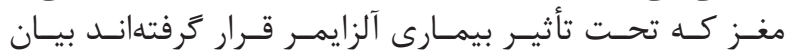

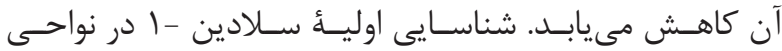

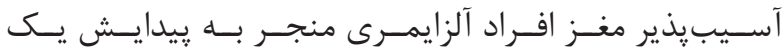

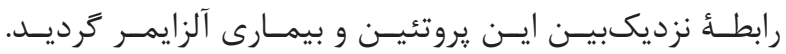

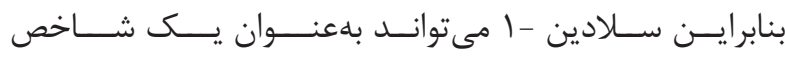

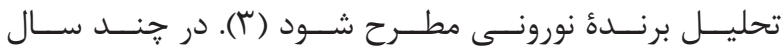

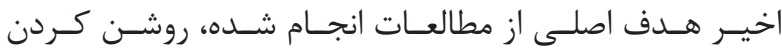

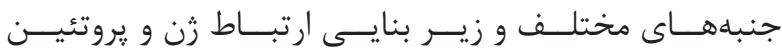

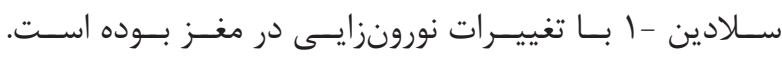

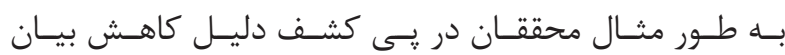

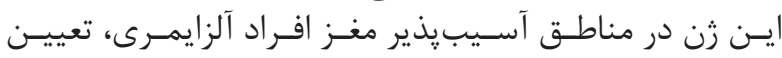

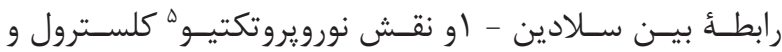

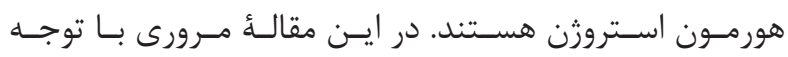

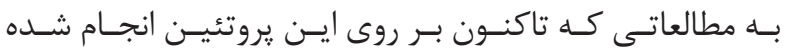

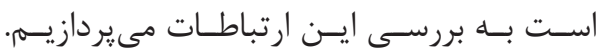

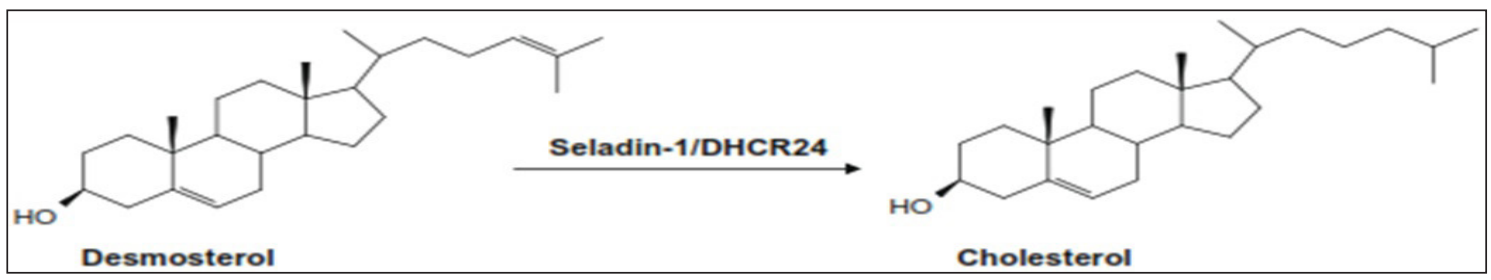

تصوير ا- تبديل دسموسترول به كلسترول توسط آنزيم سلادين -1 (9).

\footnotetext{
${ }^{1}$ Selective Alzheimer's disease (AD) indicator 1

${ }^{2}$ 24-Dehydrocholesterol reductase

${ }^{3}$ Neurogenesis

${ }^{4}$ Desmosterol

${ }^{5}$ Neuroprotective
}

${ }^{6}$ Arabidopsis thaliana

${ }^{7}$ Brassinosteroids

${ }^{8}$ Differentialm RNA

${ }^{9}$ Temporal cortex 


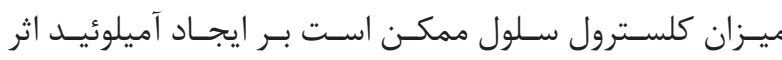

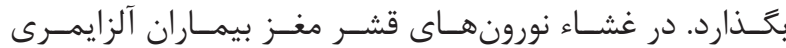

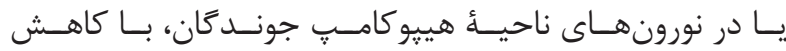

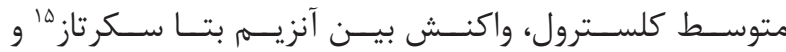

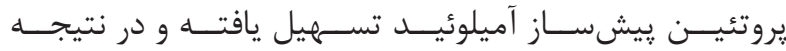

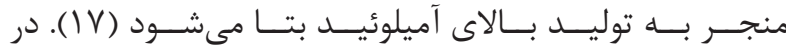

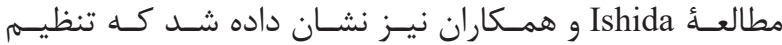

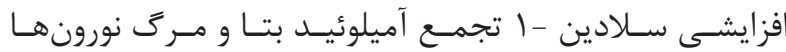

را كاهـش مى مدهـــ (1) (1).

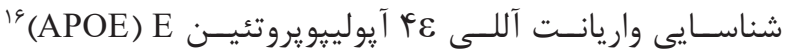

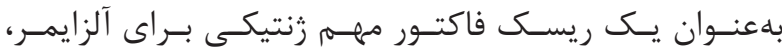

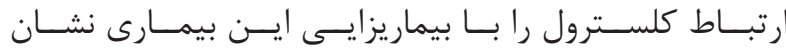

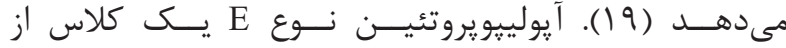

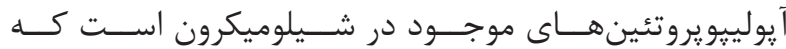

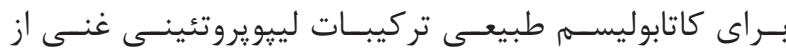

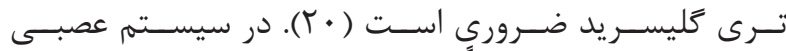

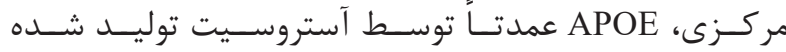

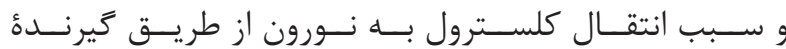

APOE

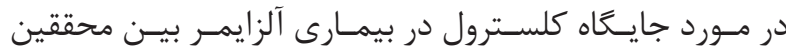

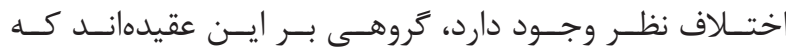

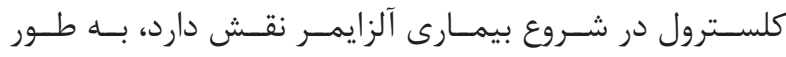

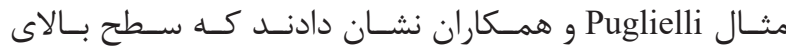

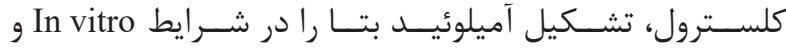

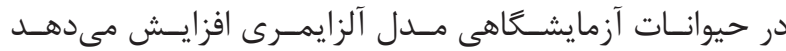

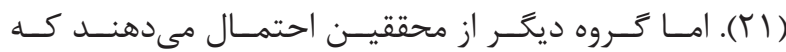

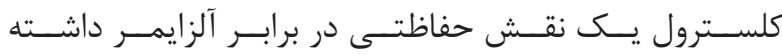

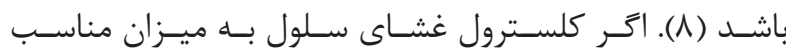

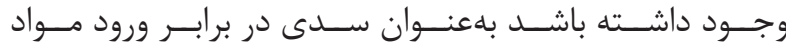

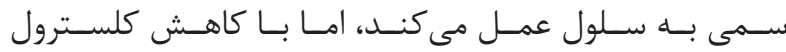

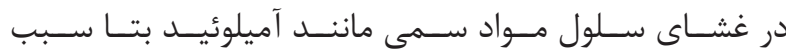

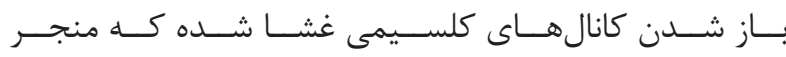

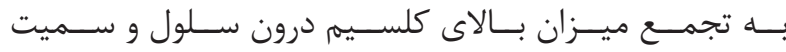

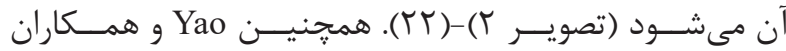

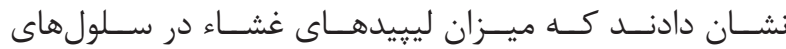

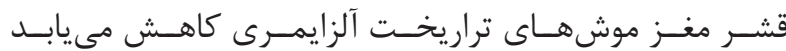

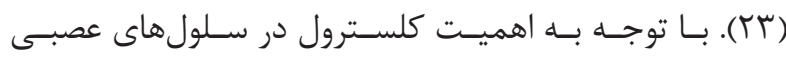

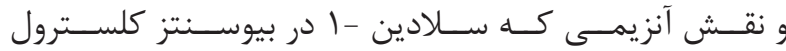

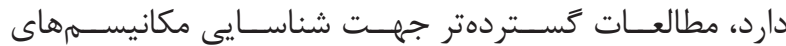

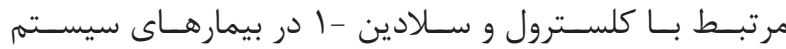

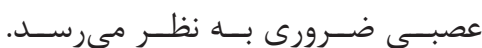

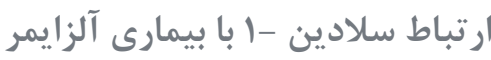

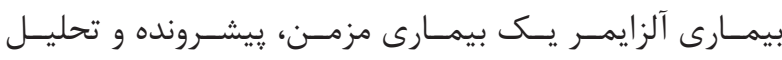

${ }^{10}$ Topological domain

${ }^{11}$ Flavinadenine dinucleotide

${ }^{12}$ Pons

${ }^{13}$ Caveolae

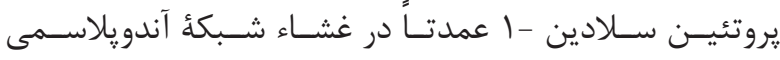

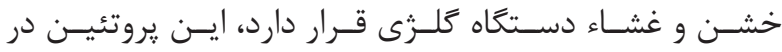

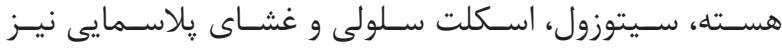

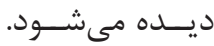

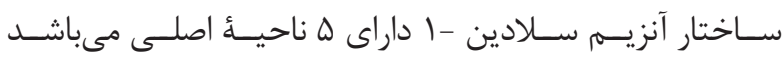

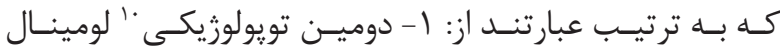

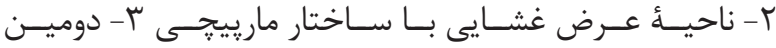

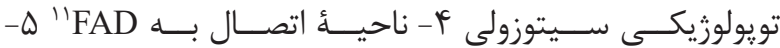

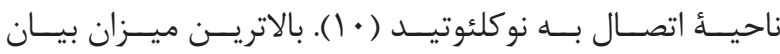

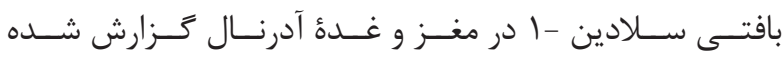

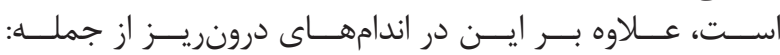

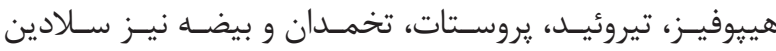

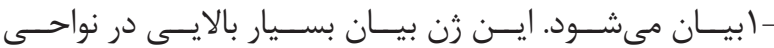

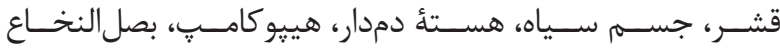

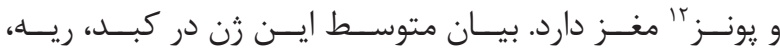

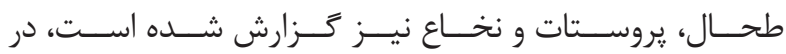

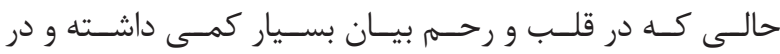

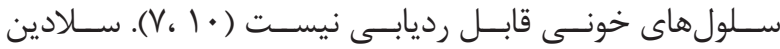

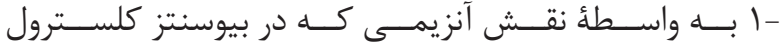

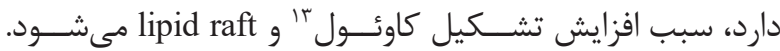

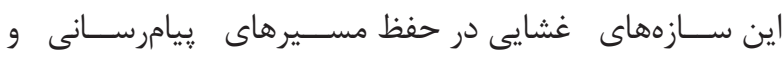

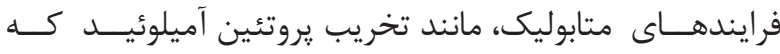

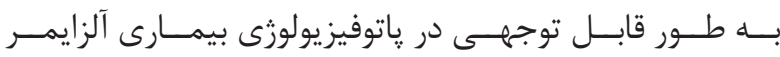

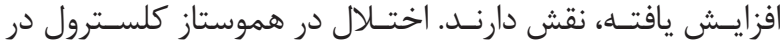

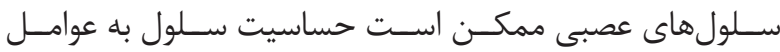

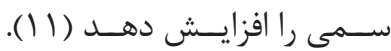

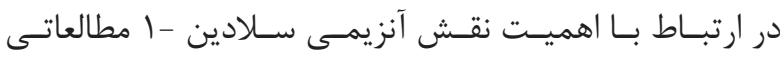

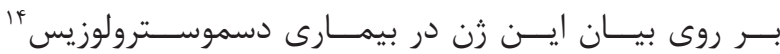

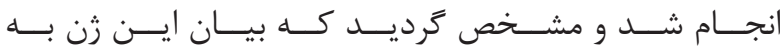

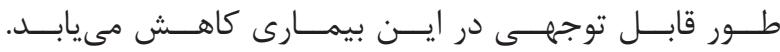

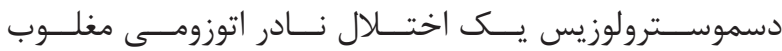

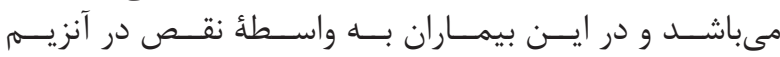

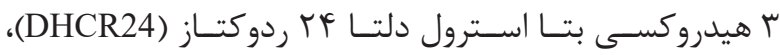

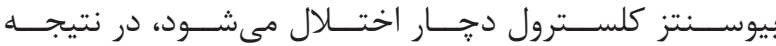

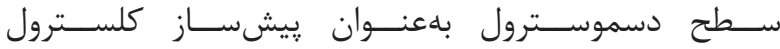

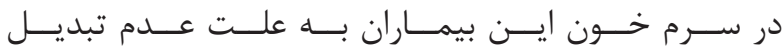

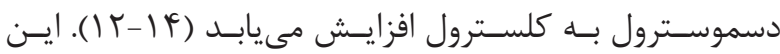

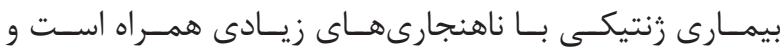

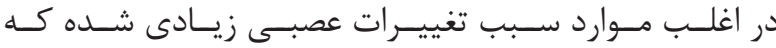

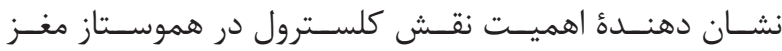

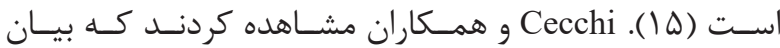

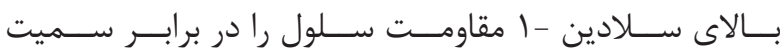

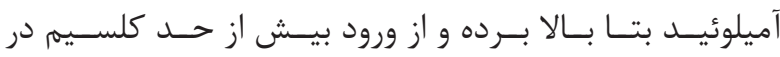

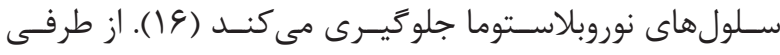

${ }^{14}$ Desmosterolosis

${ }^{15}$ Beta-secretase

${ }^{16}$ Apolipoprotein E 


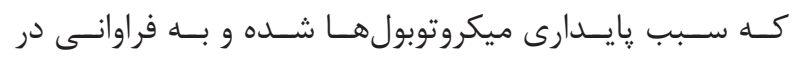

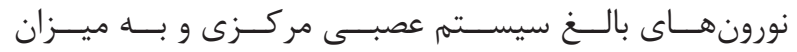

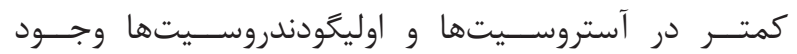

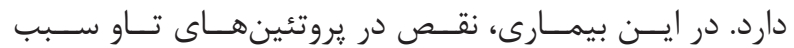

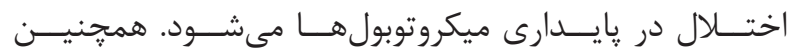

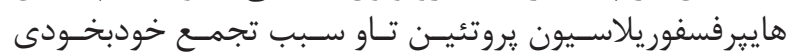

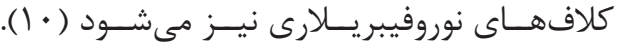

1- 1 - نقش محافظت نورونى سلادين

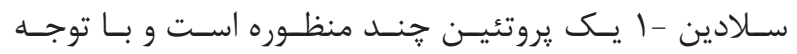

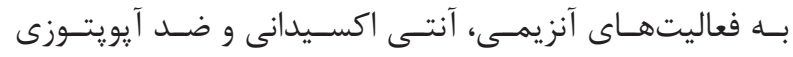

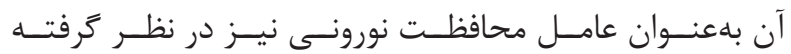

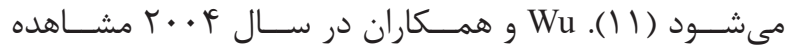

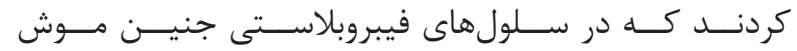

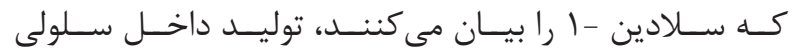

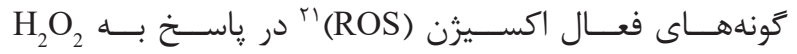

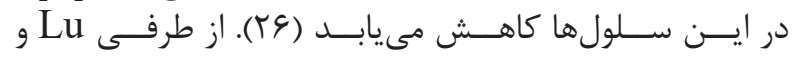

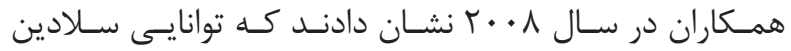

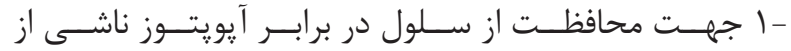

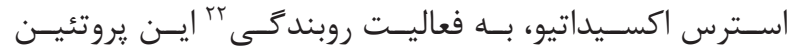

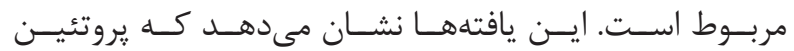

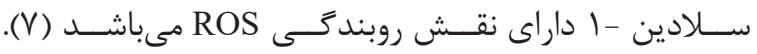

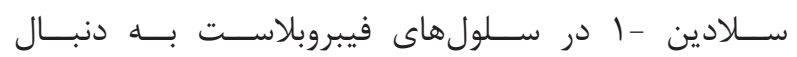

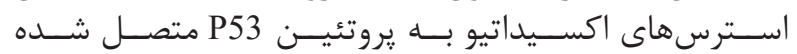

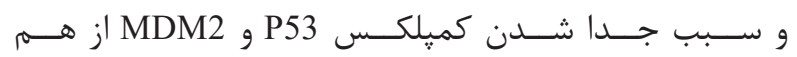

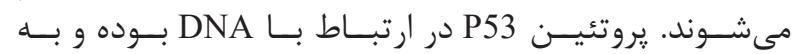

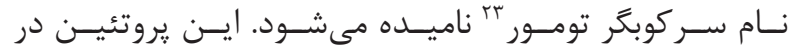

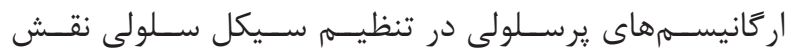

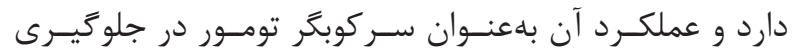

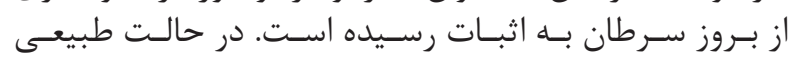

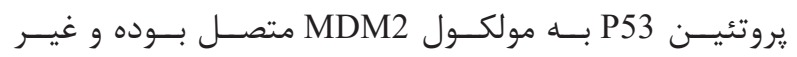

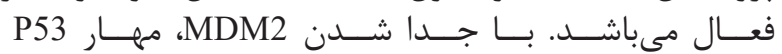

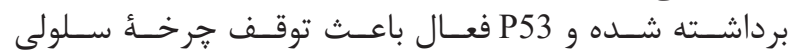

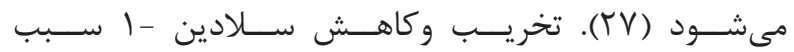

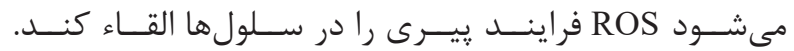

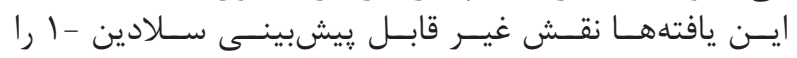

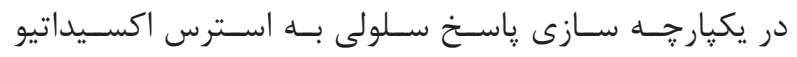

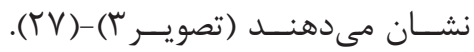

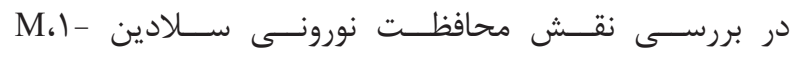

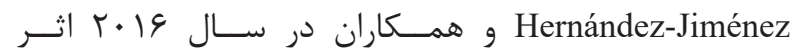

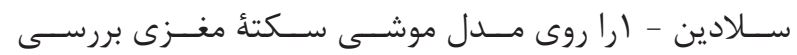

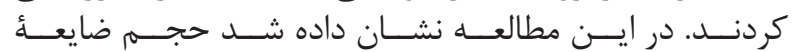

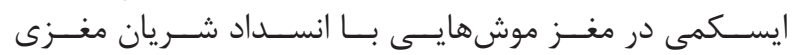

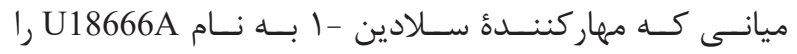

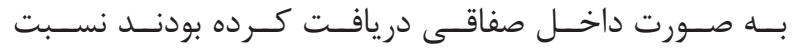

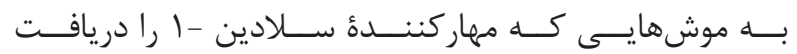

${ }^{17}$ Amyloid plagues

${ }^{18}$ Neurofibrillary tangle

${ }^{19} \mathrm{Tau}$

${ }^{20}$ Microtubule associated protein

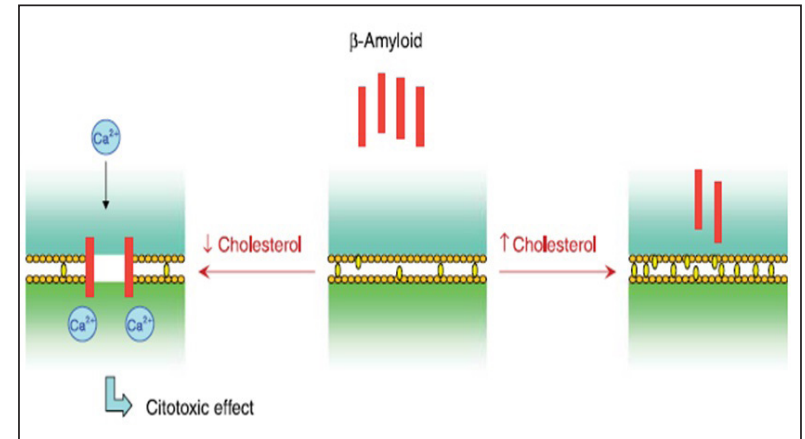

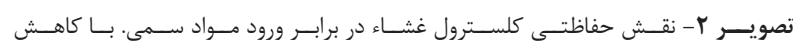

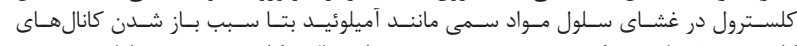

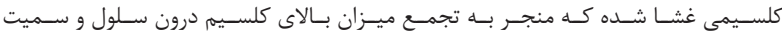

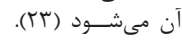

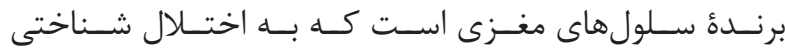

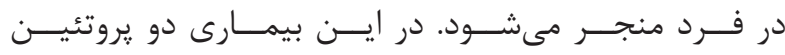

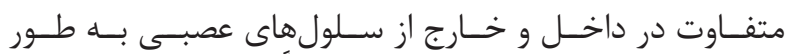

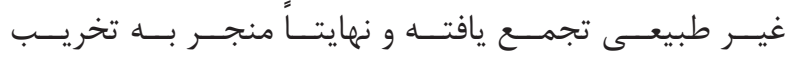

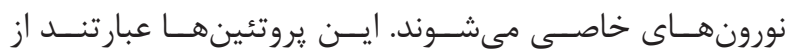

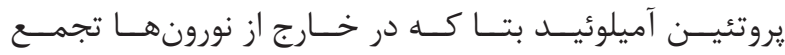

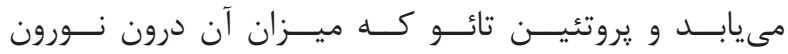

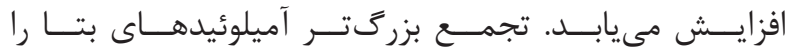

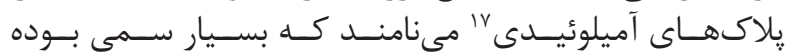

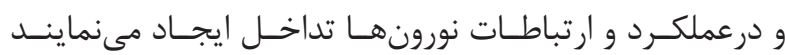
(YY)

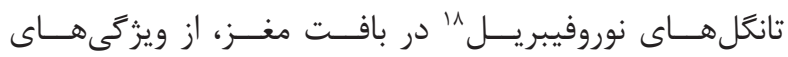

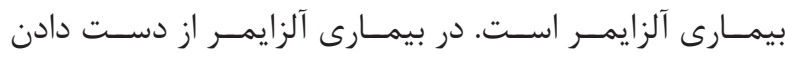

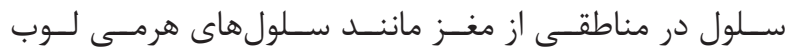

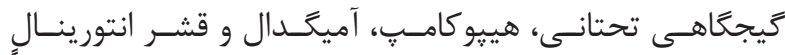

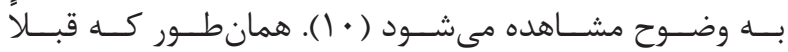

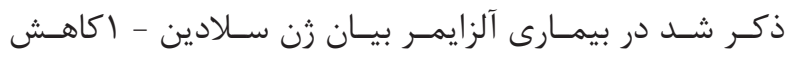

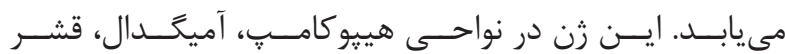

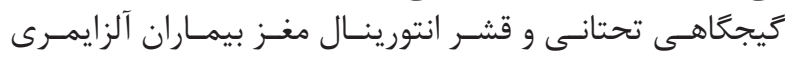

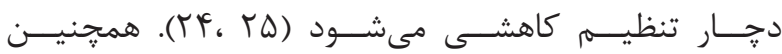

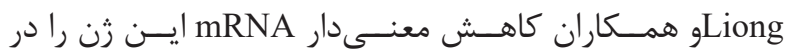

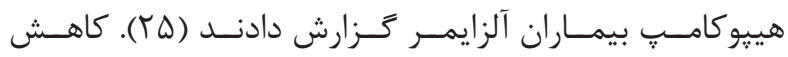

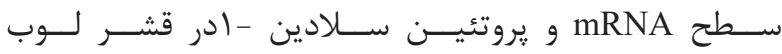

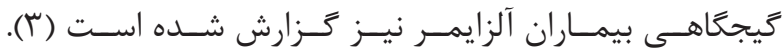

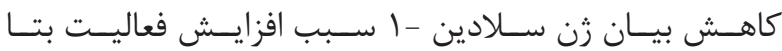

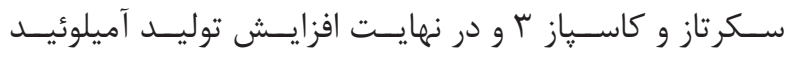

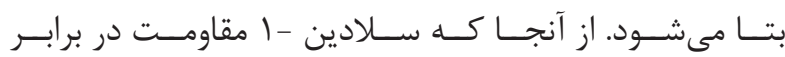

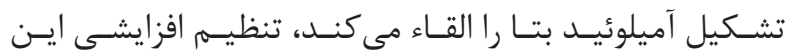

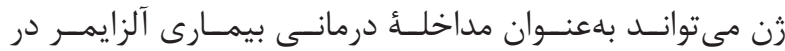

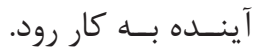

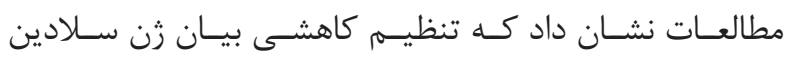

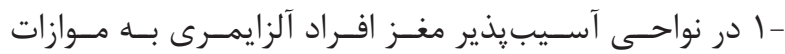

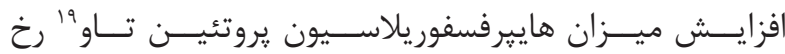

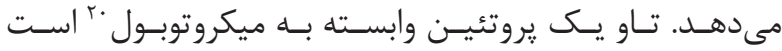

${ }^{21}$ Reactive oxygen species

${ }^{22}$ Scavenger activity

${ }^{23}$ Tumor suppressor 


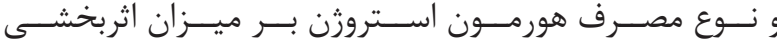

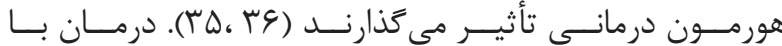

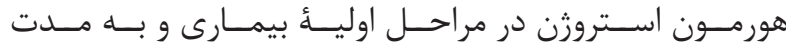

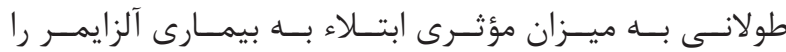

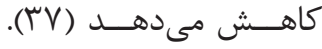

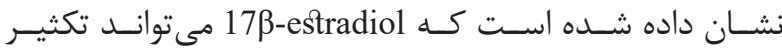

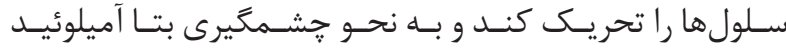

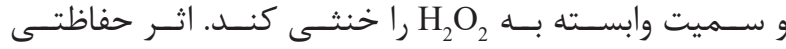

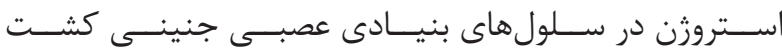

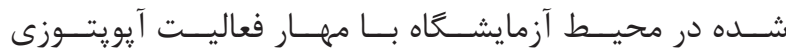

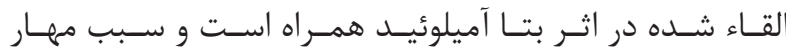

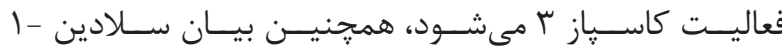

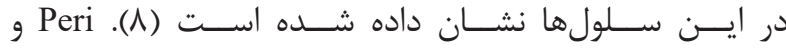

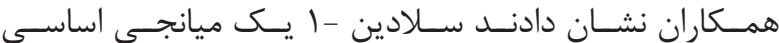

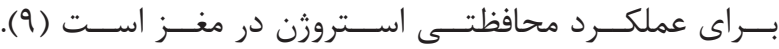

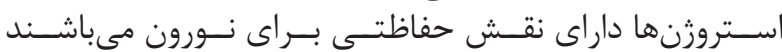

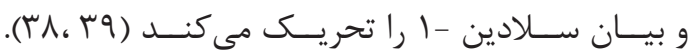
رابطة سلادين - او هورمون تيروئيد

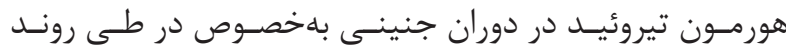

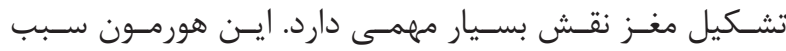

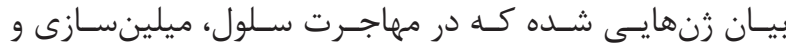

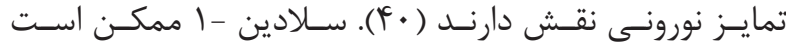

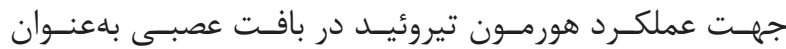

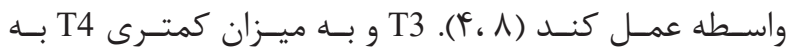

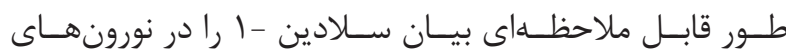

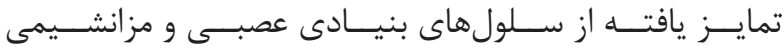

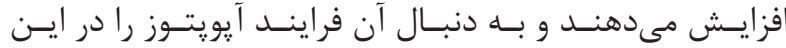

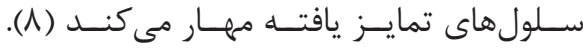
رابطة سلادين - او ويروتئين S100ß

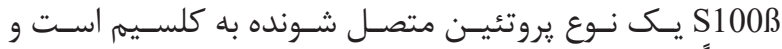

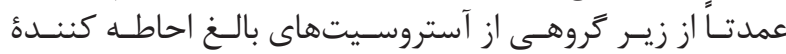

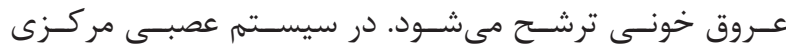

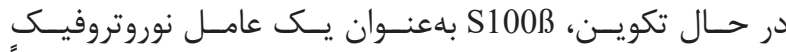

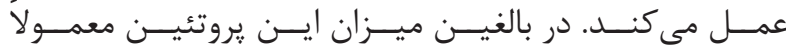

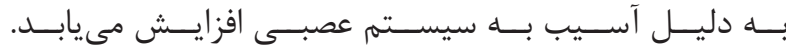

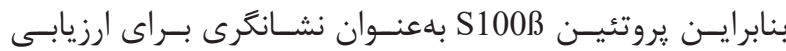

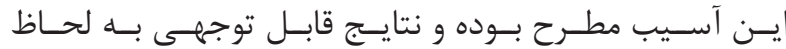

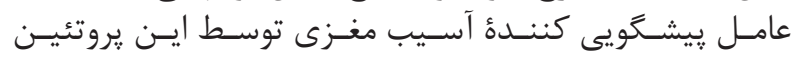

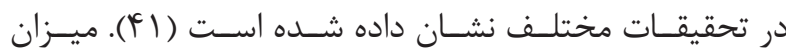

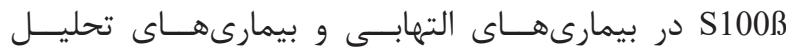

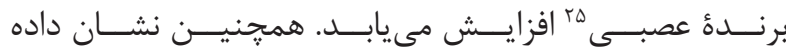

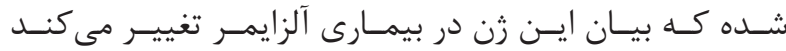

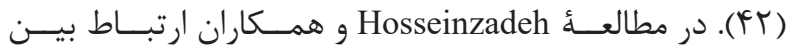

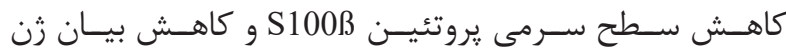

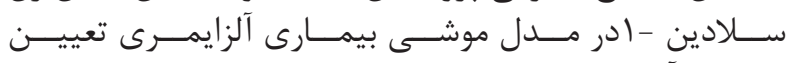

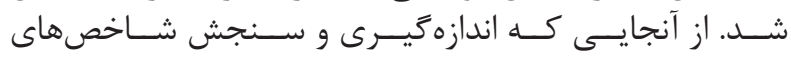
${ }^{24}$ Norditropin

${ }^{25}$ Neurodegenerative

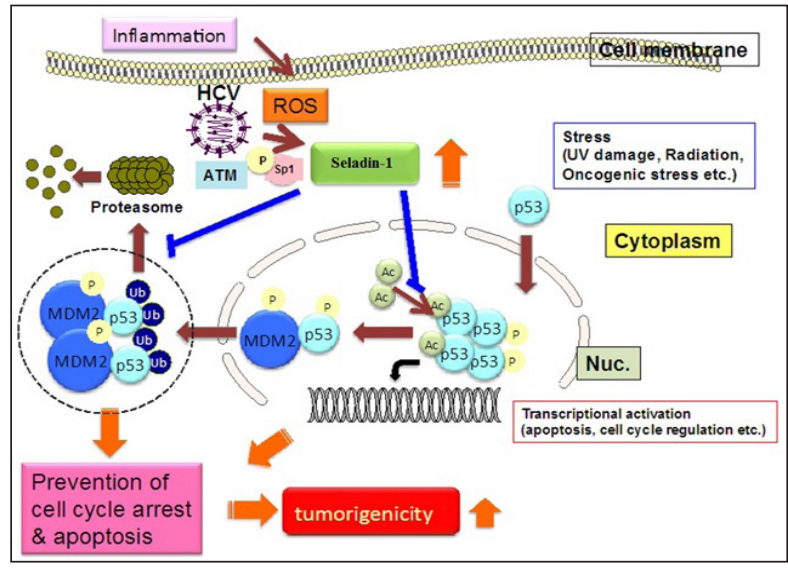

تصوير r- ارتباط سلادين - او يروتئين P53.

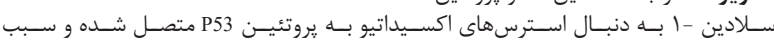

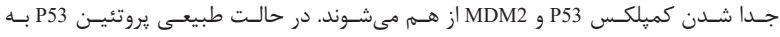

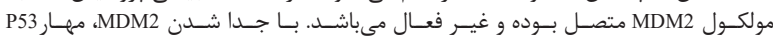

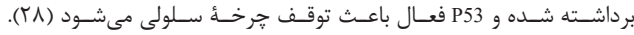

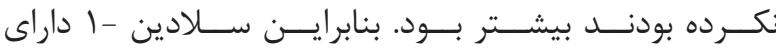

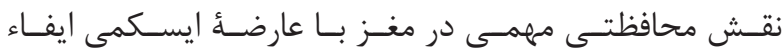

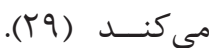

ارتباط بين سلادين - ا و هورمون استروزن

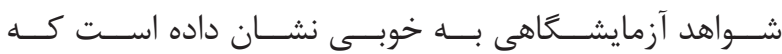

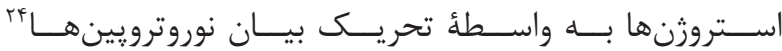

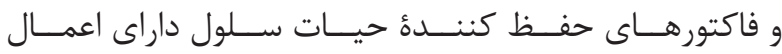

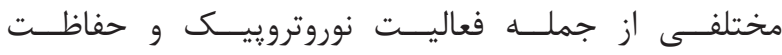

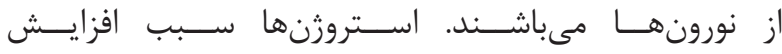

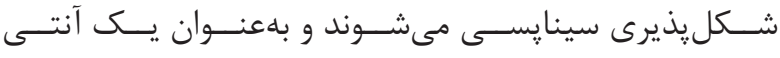

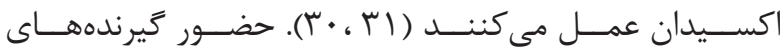

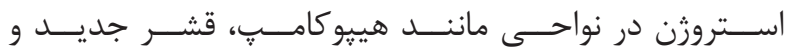

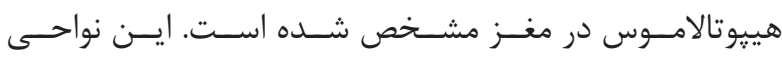

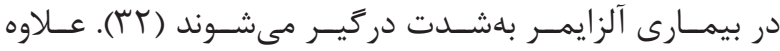

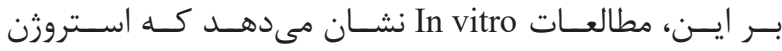

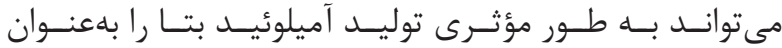

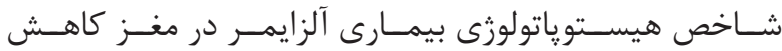

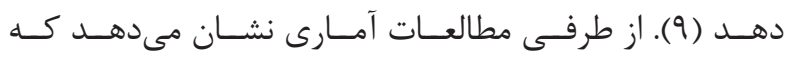

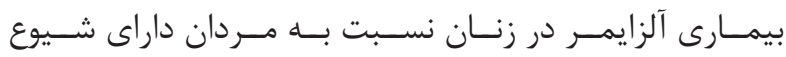

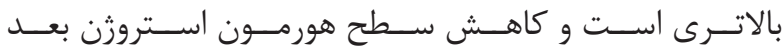

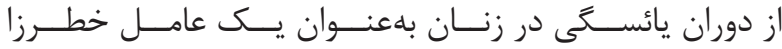

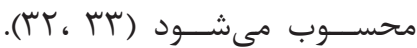

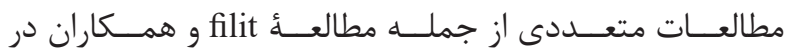

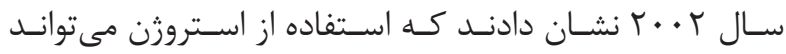

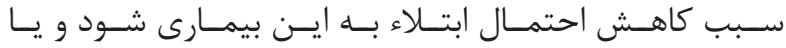

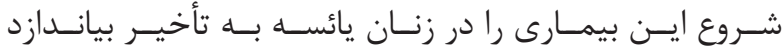

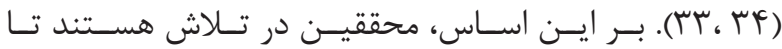

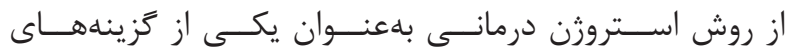

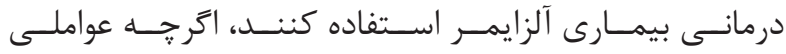

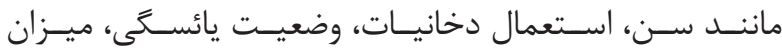




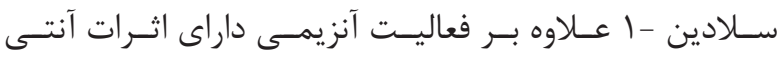

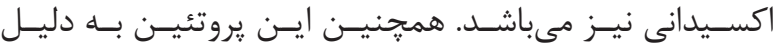

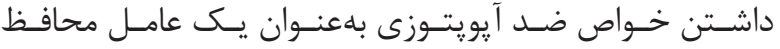

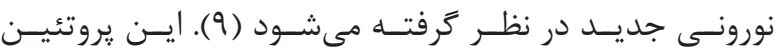

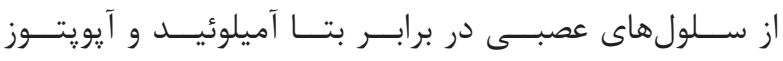

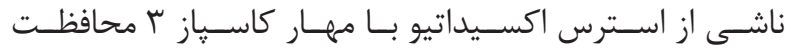

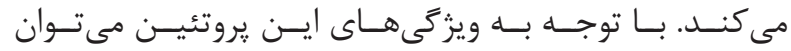

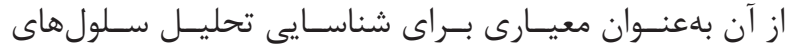

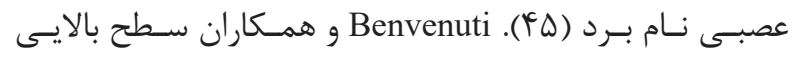

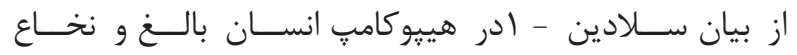

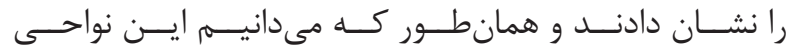

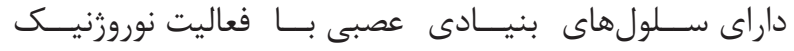

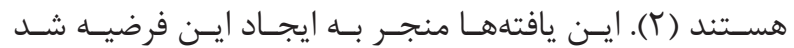

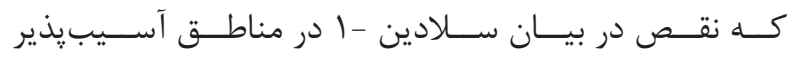

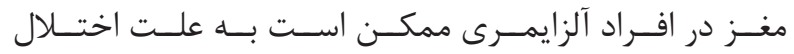

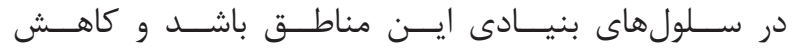

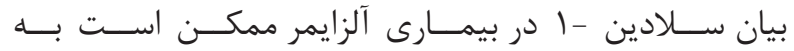

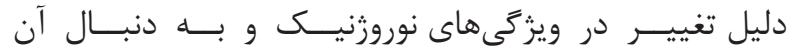

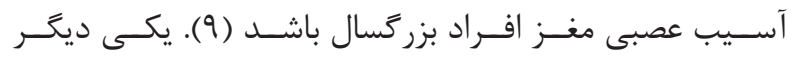

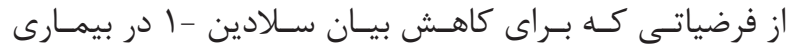

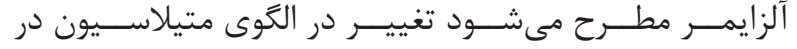

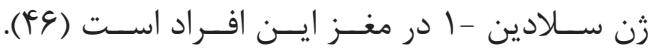

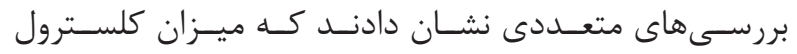

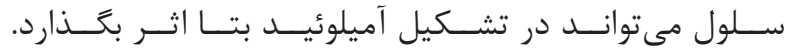

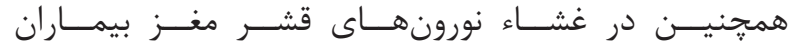

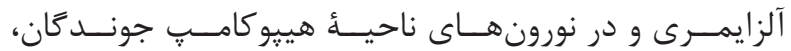

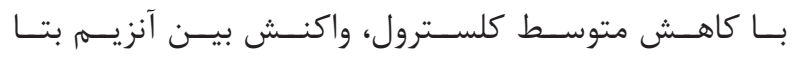

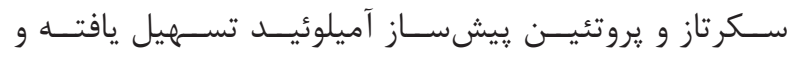

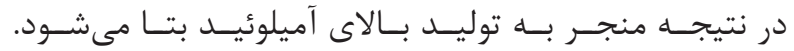

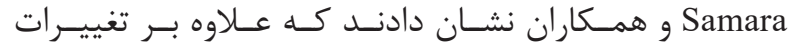

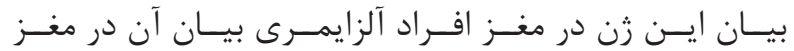

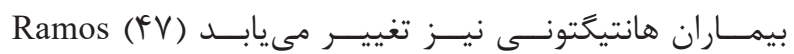

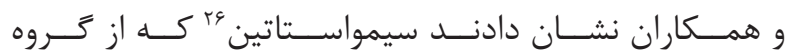

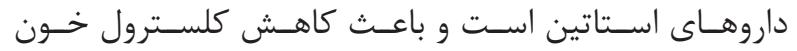

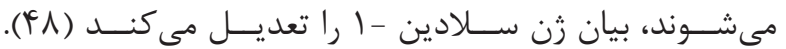

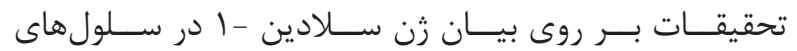

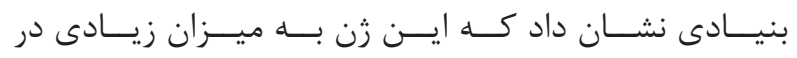

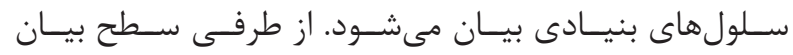

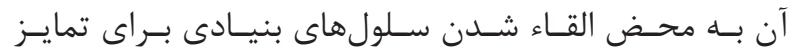

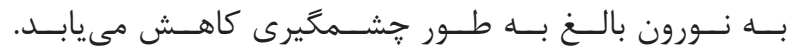

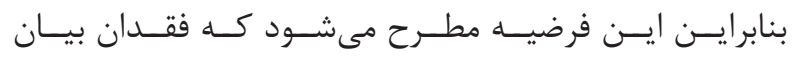

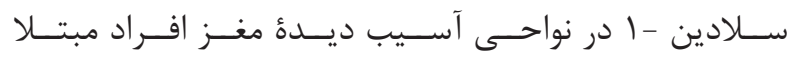

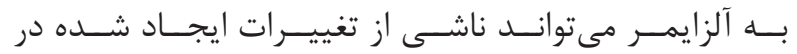

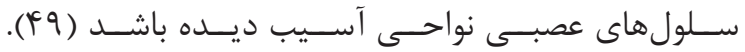

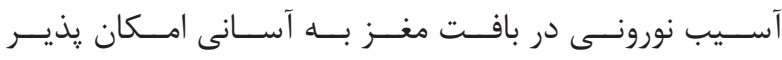

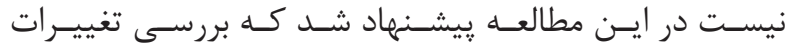

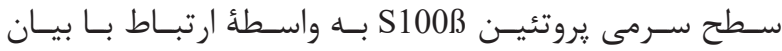

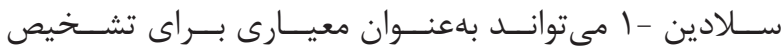

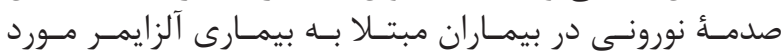
اسـتفاده قـرار كيــرد (بَأ). سلادين - او سلولهاى بنيادى

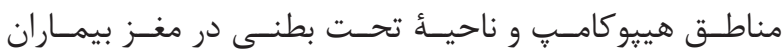

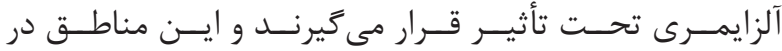

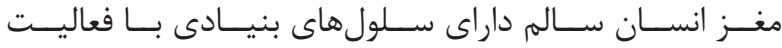

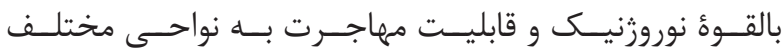

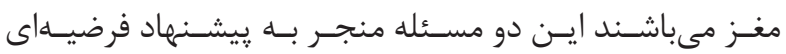

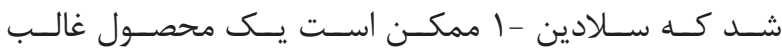

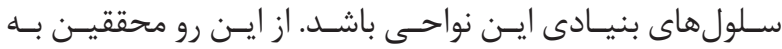

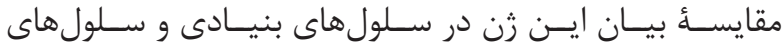

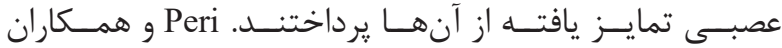

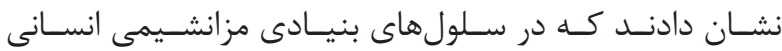

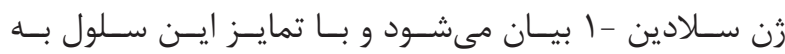

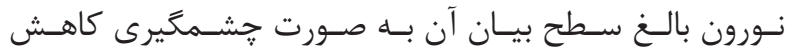

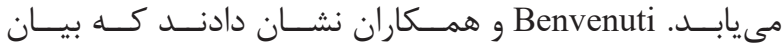

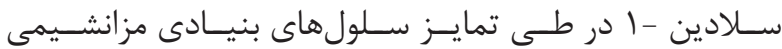

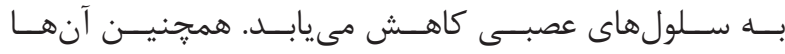

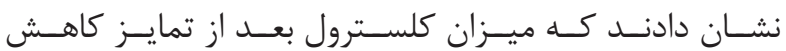

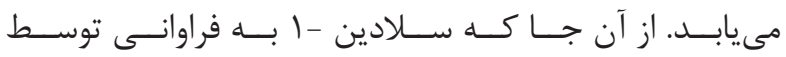

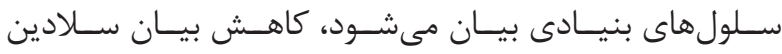

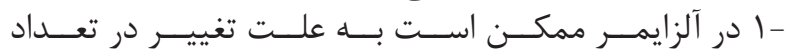

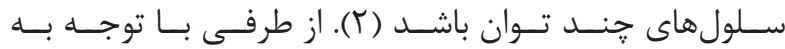

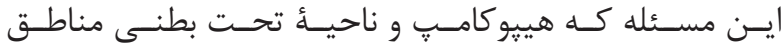

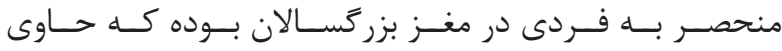

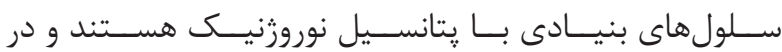

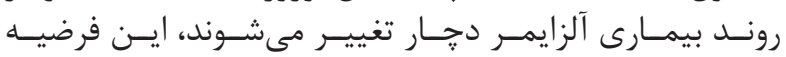

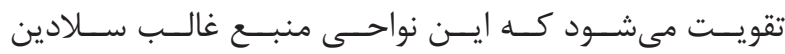

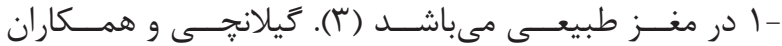

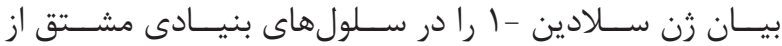

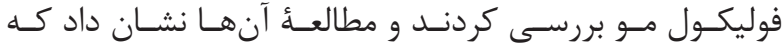

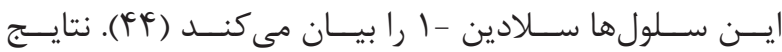

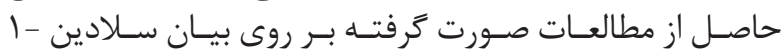

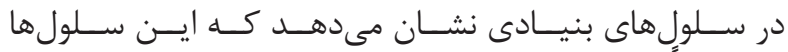

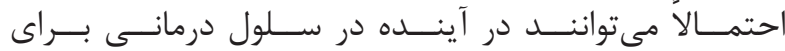

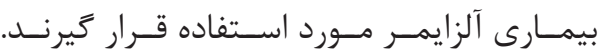

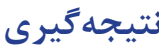

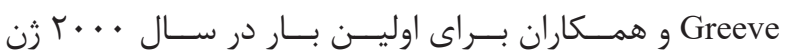

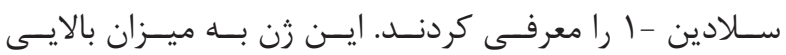

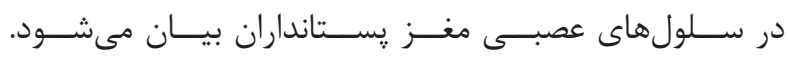


1. Waterham HR, Koster J, Romeijn GJ, Hennekam $\mathrm{RC}$, Vreken P, Andersson HC, et al. Mutations in the 3beta-hydroxysterol Delta24-reductase gene cause desmosterolosis, an autosomal recessive disorder of cholesterol biosynthesis. Am J Hum Genet. 2001; 69(4): 685-94.

2. Benvenuti S, Saccardi R, Luciani P, Urbani S, Deledda C, Cellai I, et al. Neuronal differentiation of human mesenchymal stem cells: changes in the expression of the Alzheimer's disease-related gene seladin-1. Exp Cell Res. 2006; 312(13): 2592-604.

3. Greeve I, Hermans-Borgmeyer I, Brellinger C, Kasper D, Gomez-Isla T, Behl C, et al. The human DIMINUTO/ DWARF1 homolog seladin-1 confers resistance to Alzheimer's disease-associated neurodegeneration and oxidative stress. J Neurosci. 2000; 20(19): 7345-52.

4. Benvenuti S, Luciani P, Cellai I, Deledda C, Baglioni $\mathrm{S}$, Saccardi R, et al, Thyroid hormones promote cell differentiation and up-regulate the expression of the seladin-1 gene in in vitro models of human neuronal precursors. J Endocrinol. 2008; 197(2): 437-46.

5. Miller LD, Park KS, Guo QM, Alkharouf NW, Malek $\mathrm{RL}$, Lee $\mathrm{NH}$, et al. Silencing of Wnt signaling and activation of multiple metabolic pathways in response to thyroid hormone-stimulated cell proliferation. Mol Cell Biol. 2001; 21(19): 6626-39.

6. Selkoe DJ. Alzheimer's disease: genes, proteins, and therapy. Physiology News. 2001; 81(2): 741-66.

7. Lu X, Kambe F, Cao X, Kozaki Y, Kaji T, Ishii T, et al. $3 \beta$-Hydroxysteroid- $\Delta 24$ reductase is a hydrogen peroxide scavenger, protecting cells from oxidative stress-induced apoptosis. Endocrinology. 2008; 149(7): 3267-73.

8. Peri A. Serio M. Neuroprotective effects of the Alzheimer's disease-related gene seladin-1. J Mol Endocrinol. 2008; 41(5): 251-61.

9. Peri A, Danza G, Benvenuti S, Luciani P, Deledda C, Rosati F, et al. New insights on the neuroprotective role of sterols and sex steroids: the seladin-1/DHCR24 paradigm. Front Neuroendocrinol. 2009; 30(2): 119-29.

10. Iivonen S, Hiltunen M, Alafuzoff I, Mannermaa A, Kerokoski P, Puoliväli J, et al. Seladin-1 transcription is linked to neuronal degeneration in Alzheimer's disease. Neuroscience. 2002; 113(2): 301-10.

11. Drzewińska J, Pułaski L, Soszyński M, Bartosz G. Seladin-1/DHCR24: a key protein of cell homeostasis and cholesterol biosynthesis. Postepy Hig Med Dosw. 2008; 63: 318-30.

12. Fitz Patrick DR, Keeling JW, Evans MJ, Kan AE, Bell JE, Porteous ME, et al. Clinical phenotype of desmosterolosis. Am J Med Genet. 1998; 75(2): 145-52.

13. Schaaf CP, Koster J, Katsonis P, Kratz L, Shchelochkov OA, Scaglia F, et al. Desmosterolosisphenotypic and molecular characterization of a third case and review of the literature. Am J Med Genet A Part A? 2011; 155(7): 1597-604.

14. Herman GE. Disorders of cholesterol biosynthesis: prototypic metabolic malformation syndromes. Hum Mol Genet. 2003; 12(1): R75-R88.

15.Klahre U, Noguchi T, Fujioka S, Takatsuto S, Yokota $\mathrm{T}$, Nomura $\mathrm{T}$, et al. The arabidopsis DIMINUTO/ DWARF1 gene encodes a protein involved in steroid synthesis. Plant Cell. 1998; 10(10): 1677-90.

16. Cecchi C, Rosati F, Pensalfini A, Formigli L, Nosi D, Liguri G, et al. Seladin-1/DHCR24 protects neuroblastoma cells against $A \beta$ toxicity by increasing membrane cholesterol content. J Cell Mol Med. 2008; 12(5b): 1990-2002.

17. Abad-Rodriguez J, Ledesma MD, Craessaerts K, Perga S, Medina M, Delacourte A. Neuronal membrane cholesterol loss enhances amyloid peptide generation. J Cell Biol. 2004; 167(5): 953-60.

18. Ishida E, Hashimoto K, Okada S, Satoh T, Yamada M, Mori M. Crosstalk between thyroid hormone receptor and liver $\mathrm{X}$ receptor in the regulation of selective Alzheimer's disease indicator-1 gene expression. PloS One. 2013; 8(1): e54901.

19. Liu CC, Kanekiyo T, Xu H, Bu G .Apolipoprotein $\mathrm{E}$ and Alzheimer disease: risk, mechanisms and therapy. Nat Rev Neurol. 2013; 9(2): 106-18.

20. Burke SL, Maramaldi P, Cadet T, Kukull W. Associations between depression, sleep disturbance, and apolipoprotein E in the development of Alzheimer's disease: dementia. Int Psychogeriatr. 2016: p. 1.

21. Di Paolo G, Kim TW. Linking lipids to Alzheimer's disease: cholesterol and beyond. Nat Rev Neurosci. 2011; 12(5): 284-96.

22. Arispe N1, Doh M, Plasma membrane cholesterol controls the cytotoxicity of Alzheimer's disease A $\beta$ P (1-40) and (1-42) peptides. FASEB J. 2002; 16(12): 1526-36. 
23. Yao JK, Wengenack TM, Curran GL, Poduslo JF. Reduced membrane lipids in the cortex of Alzheimer's disease transgenic mice. Neurochem Res. 2009; 34(1): 102-8.

24. Alipour F, Borhani Haghighi M, Pasand Mojdeh H.The Role of stem cell therapy in Alzheimer's disease. Shefaye Khatam. 2016; 4(2): 87-97

25. Liang WS, Dunckley T, Beach TG, Grover A, Mastroeni D, Ramsey K, et al. Altered neuronal gene expression in brain regions differentially affected by Alzheimer's disease: a reference data set. Physiol Genomics. 2008; 33(2): 240-56.

26. Wu C, Miloslavskaya I, Demontis S, Maestro R, Galaktionov K. Regulation of cellular response to oncogenic and oxidative stress by Seladin-1. Nature. 2004; 432(7017): 640-5.

27. Kuehnle K, Crameri A, Kälin RE, Luciani P, Benvenuti S, Peri A, et al. Prosurvival effect of DHCR24/Seladin-1 in acute and chronic responses to oxidative stress. Mol Cell Biol. 2008; 28(2): 539-50.

28. Tsukiyama-Kohara K. Role of oxidative stress in hepatocarcinogenesis induced by hepatitis $\mathrm{C}$ virus. Int $\mathrm{J}$ Mol Sci. 2012; 13(11): 15271-8.

29. Hernández-Jiménez M, Martínez-López D, Gabandé-Rodríguez E, Martín-Segura A, Lizasoain I, Ledesma MD. Seladin-1/DHCR24 is neuroprotective by associating EAAT2 glutamate transporter to lipid rafts in experimental stroke. Stroke. 2016; 47(1): 206-13.

30. Behl C. Estrogen can protect neurons: modes of action. J Steroid Biochem Mol Biol. 2002; 83(1): 195-7.

31. Turgeon JL, Carr MC, Maki PM, Mendelsohn ME, Wise PM. Complex actions of sex steroids in adipose tissue, the cardiovascular system, and brain: Insights from basic science and clinical studies. Endocrine Reviews. 2006; 27(6): 575-605.

32. Lee JH, Jiang Y, Han DH, Shin SK, Choi WH, Lee MJ. Targeting estrogen receptors for the treatment of Alzheimer's disease. Mol Neurobiol. 2014; 49(1): 39-49.

33. Vest RS, Pike CJ. Gender, sex steroid hormones, and Alzheimer's disease. Horm Behav Hormones and Behavior. 2013; 63(2): 301-7.

34. Fillit HM. The role of hormone replacement therapy in the prevention of Alzheimer disease. Arch Intern Med. 2002; 162(17): 1934-42.

35. LeBlanc A. Estrogen and Alzheimer's disease.
CURR OPIN INVEST DR (London, England: 2000). 2002; 3(5): 768-73.

36. Silva I, Naftolin F, Brain health and cognitive and mood disorders in ageing women. Best Pract Res Clin Obstet Gynaecol. 2013; 27(5): 661-72.

37. Zandi PP, Carlson MC, Plassman BL, WelshBohmer KA, Mayer LS, Steffens DC, et al. Hormone replacement therapy and incidence of Alzheimer disease in older women: the cache county study. JAMA. 2002; 288(17): 2129-3.

38. Peri A, Serio M. Estrogen receptor-mediated neuroprotection: The role of the Alzheimer's diseaserelated gene seladin-1. Neuropsychiatr Dis Treat. 2008; 4(4): 817-24.

39. Peri A. Neuroprotective effects of estrogens: the role of cholesterol. J Endocrinol Invest. 2016; 39(1): 11-8.

40. Luciani P, Deledda C, Rosati F, Benvenuti S, Cellai I, Dichiara F, et al. Seladin-1 is a fundamental mediator of the neuroprotective effects of estrogen in human neuroblast long-term cell cultures. Endocrinology. 2008; 149(9): 4256-66.

41. Anderson DC. Alzheimer's disease biomarkers: more than molecular diagnostics. Drug Dev Res. 2013; 74(2): 92-111.

42. Cirillo C, Capoccia E, Iuvone T, Cuomo R, Sarnelli $\mathrm{G}$, Steardo L, et al. S100B inhibitor pentamidine attenuates reactive gliosis and reduces neuronal loss in a mouse model of alzheimer's disease. Biomed Res Int. 2015.

43. Hosseinzadeh S, Zahmatkesh M, Hassanzadeh Gh-R, Karimian M, Heidari M, Karami M. The correlation of serum S100 $\beta$ protein levels and hippocampal Seladin-1 gene expression in a rat model of sporadic Alzheimer's disease. Tehran Univ Med J. 2015; 73(8): 569-76.

44. Gilanchi S, Esmaeilzade B, Eidi A, Barati M, Mehrabi S, Moghani Ghoroghi F, et al. Neuronal differentiation of rat hair follicle stem cells: the involvement of the neuroprotective factor Seladin-1 (DHCR24). Iran Biomed J. 2014; 18(3): 136.

45. Kodukula Anderson DC, Kodukula K, Biomarkers in pharmacology and drug discovery. Biochem Pharmacol. 2014; 87(1): 172-88.

46. Simi L, Malentacchi F, Luciani P, Gelmini S, Deledda C, Arvia R, et al. Seladin-1 expression is regulated by promoter methylation in adrenal cancer. BMC Cancer. 2010; 10(1): 201. 
47. Samara A, Galbiati M, Luciani P, Deledda C, Messi E, Peri A, et al. Altered expression of 3-betahydroxysterol delta-24-reductase/selective Alzheimer's disease indicator-1 gene in Huntington's disease models. J Endocrinol Invest. 2014; 37(8): 729-37.

48. Ramos MC, Sierra S, Ramirez C, Velasco J, Burgos JS. Simvastatin modulates the Alzheimer's disease- related gene seladin-1. J Alzheimers Dis. 2012; 28(2): 297-301.

49. Benvenuti S, Luciani P, Vannelli GB, Gelmini S, Franceschi E, Serio M, et al. Estrogen and SERMs exert neuroprotective effects and stimulate the expression of seladin-1, a recently discovered anti-apoptotic gene, in human neuroblast long-term cell cultures. J Clin Endocrinol Metab. 2005; 90: 1775-82. 